\title{
Arabic Political Caricature. History and Poetics
}

\author{
A. Anisimov \\ Taras Shevchenko National University of Kyiv, Ukraine \\ Corresponding author. E-mail: sublustrum1@gmail.com
}

Paper received 20.11.21; Accepted for publication 13.01.21.

https://doi.org/10.31174/SEND-HS2021-249IX44-01

Abstract. In the modern Arab world caricatures have undergone an evolution from humorous illustrated anecdotes to a considerably influential and socially valuable form of literature and visual art [5, p. 11], within approximately a century of development. However caricatures are still relatively novel and unorthodox, mainly because of their capacity to depict social problems in a way that would interest native and foreign readership through elementary symbolism and simple language. Also, linguistically, caricatures are usually rich with references to historical data, which make them suitable material for the present study. The article revises the linguistic and visual features of the genre based on Arabic caricatures dedicated to the Second Lebanon War (2006).

Keywords: cartoon, caricature, détournement, Middle East, politics, war.

Poetics of caricature as a "hybrid" genre can be studied, taking into account their two intertwined components: visual symbolism and semantics (provided that text adds a new dimension to the picture).

By way of illustration, Emad Hajjaj in his drawing printed in Al Quds Al Arabi [5, p. 24] depicts a cedar tree - the national symbol of Lebanon - as a pile of rubble and dead bodies, where the root of the tree takes the form of a hand, reaching for the AK-47; which, for its part, is an allusion to the Hezbollah logo (image 1a). The real emotional content behind the picture (redemption? mourning?) may be known only to the author, however, the picture gives an accurate idea of what the most influential military power in Lebanon was and what the war has amounted to in the end. In such a way, cartoons like this can provide the reader with an insight into history (pre-history) of the conflict using only one visual metaphor.
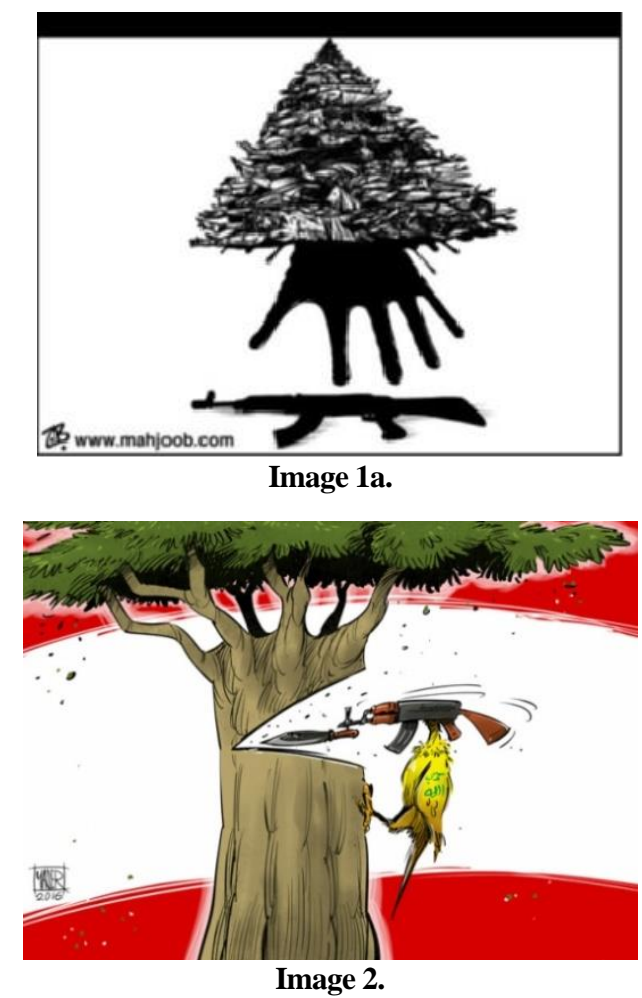

Whereas in terms of linguistics, caricature can offer an ironic representation of the political time using metaphors like "throwing the red carpet" ("bast") which, in case of Amjad Rasmi's cartoon (image 3), is the job of the Lebanese Prime Minister - As-Sinyora - who is stretching the lands of his country like a carpet, motivated to do so by the Israeli devastation ("ijtiyāh") forces. In this key, caricature may serve as a visual deconstruction of multiple terms and expressions which are used regularly by the media.

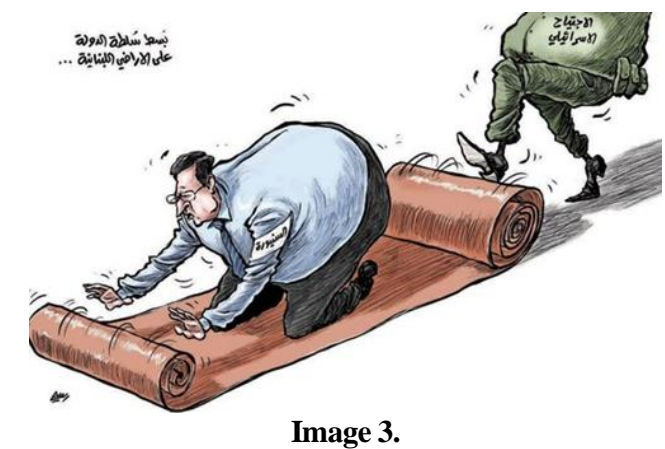

In the same way, today it covers all the important political events and factions in the Middle East. In fact, it has been for a long time (starting from XIX century), since caricature became a part of Arab mass media. In spite of Islamic culture not being the most conducive an environment for pictorial art, political cartoons were introduced regardless. This, according to Göçek [3, p. 8], was a result of western influence on the Ottoman Empire in the mid-nineteenth century: "[Political cartoons] accompanied Europe's gradual technological, economic, and political domination over the rest of the world. The non-Western world including the Middle East promptly started to employ this medium to scorn their own Westernizing selves and to ridicule and delegitimize their Western rulers. Local myths, folktales, and aesthetic forms were quickly synthesized into these new interpretations, first to symbolically authenticate the burgeoning nationalist movements and then to resist them".

Thus, the traditionally western art-form was adapted by eastern cartoonists. Therefore, there is a question about authenticity of Arabic caricatures - do they copy the style of their western colleagues or have a fresh approach to the matter? A possible answer is presented by Susan and Joseph Slymovics in their monograph dedicated to the Gulf war 
caricatures [6, p. 73]: "There are affinities and a shared visual vocabulary between Western and Arab notions of caricature, but the traditions and public roles which they are linked to are very different"; showing what exactly the difference is - is going to be revised hereinafter.

In any case, Arab caricaturists first internationally succeeded in offering a fresh perspective on the reported information during the Gulf war, while having mocked the official version of events. Moreover, their oeuvres incited the viewer to ponder on the issues that are often misrepresented on television. In other words: "Caricatures explicitly reduce the political expression of a country, say Iraq or the United States, to a single individual: Saddam Hussein, Bush, or to a woman who symbolizes that country. At the same time, the graphic image allows for a speculative and interrogative dimension. In contrast, television discourages reflection upon complex issues of context, history, gender, culture, and international relations. Images are discrete and self-contained and exclude any discussion. Television, then, is a more powerful caricature, if you will, than any cartoon" [Ibid. p. 97].

In addition to that, in the 1990s, creation of global, digitally powered Arab media (Al-Jazeera, Al-Arabiya and Abu Dhabi) provided caricaturists with a new lane to develop the genre, owing to the necessity of newly created media to compete with each other by presenting a more provocative and, as a result, more engaging take on a given political event. In this situation, political cartoons became quite a tool of swaying public opinion on various topics: "Print media content critical of domestic government policies is common in the press systems of Egypt, Morocco, Kuwait, Jordan, and Lebanon. More space is being devoted to readers' views and to those of intellectuals on issues ranging from Arab solidarity, to the stalled Middle East processes, to the rehabilitation of Iraq" [Aish in Hafez, p. 124].

Thus, studying the ways through which the audience was provoked - in terms of visual presentation and text - constitutes the objective of the present article.

In terms of methodology, the influence that caricatures wield over their readership will be analyzed by means of deconstruction, or, in other words, by uncovering historical aspects of caricature and contrasting them to the viewpoint offered by the author. This method is uniquely suited for analyzing political cartoons, as most of them combine two dimensions - linguistic and visual - which normally automatically "deconstruct" each other by means of détournement (French "hijacking”); i.e. a way of subverting a political message. The method was offered by a French writer and philosopher Guy Debord in the 1950 [11], and the essence of such "cultural hijacking" - in the context of the present article - lies in the integration of past and present (national and international, Israeli and Arab etc.) sides of the same ideological meme with the purpose of overturning the initial propagandistic charge. This usually means rearranging or omitting words and phrases in populist (corporate) slogans, e.g. "reformatting" of the iconic Marlboro billboard, so it reads "It's a bore" (image 1.1)

The history of implementation of a similar technique is covered in the present study in the chronological order of the main events of the war, for the sake of a more profound understanding of the logic of the conflict and, therefore, motivation of the cartoonists.

Thereby, the proverbial "big picture" is contained within numerous caricatures dedicated to Lebanon war, 2006. De- spite the large number of caricatures created during the time, as well as numerous long-standing political effects on the region, the conflict as such was short and devastating - 34 days of fighting between Israel Defense Forces (IDF) and Hezbollah, on the territory limited to Lebanon, Northern Israel and the Golan Heights. Naturally, the war has resulted in numerous deaths among civilians as a number of historical events have been transformed into literary and visual art form, the analysis of which will follow shortly [13].

First of all, it is necessary to remark that visual symbolism of the reviewed political cartoons is quite elementary, as well as its vocabulary. Little erudition is needed when the author draws a bird in the colors of Hezbollah (image 2), whose beak (an AK-47 automatic rifle) is gradually destroying the Lebanese cedar tree. On examples like this we may observe that such iconography has a lot more to do with a combination of hand-picked symbols that convey a simple metaphoric phrase, rather than with conventional genres of visual art, which usually offer an opportunity for a variety of "readings". This makes caricature stand closer to illustrated literature, on the crossroads between written word and comics.
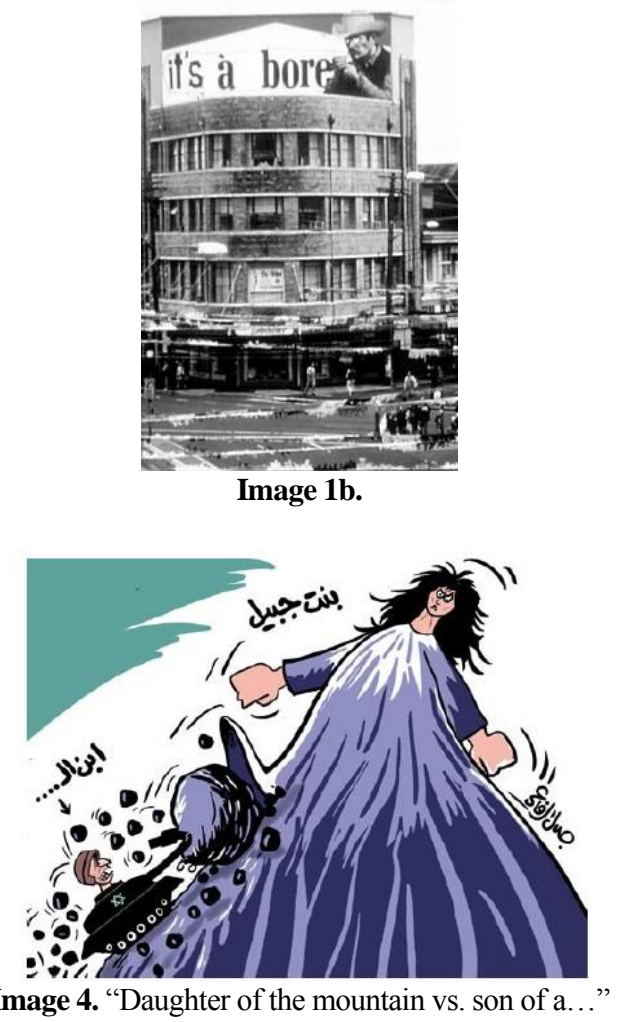

Second, with the help of the fore-mentioned example, we may take note of the most distinctive features of caricature as a genre: universality, pertinent historical context, as well as candor that does not call for interpretation of author's point of view.

In the light of the above, ideological acuteness of caricature is a big part in what makes this genre popular and above all, by the standards of XXI c., "re-postable"; especially when it is directed against the opposing faction. Such is the case with the drawings of Jalal ar-Rifa'y who generally depicted Israeli politicians as blood thirsty and too incompetent to obtain their presumed goals. Expectedly, nearly every Arabic mass media outlet in 2006 was picturing Israel as the aggressor, justifying nearly all the actions of their opponents - Hezbollah [5, p. 41]. 
The flipside of this coin is that Hezbollah, being a terrorist organization, almost always is supported by the majority of Arab cartoonists when it comes to depicting important events of the war. Thus, the battle of Bint Jbeil (July 23 - August 11) which has not been objectively won by any side, as both of them suffered heavy losses [7], was depicted by Jalal arRifa'y as a strategic victory of Hezbollah (image 4). In this case, the caricaturist uses visual personalization, as the mountain (the literal translation of the name of the mountain being "daughter of the mountain") is depicted as a young woman who stops the "son of a...", impersonalized by an Israeli tank.
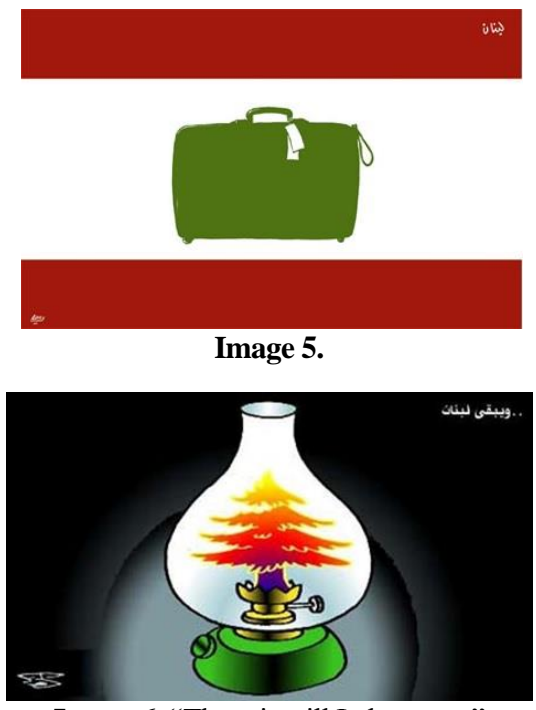

Image 6. "There is still Lebanon..."

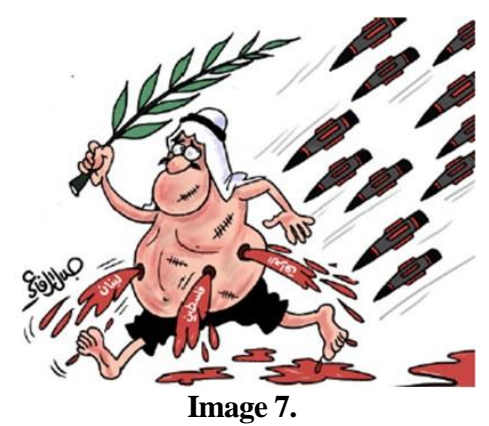

As for the third side of the conflict - Lebanon - it has undoubtedly suffered the heaviest destruction. In the aftermath of the war, a big part of the country's population - as is shown in the cartoon by Amjad Rasmi (5) - were forced to abandon their native land in search for more plausible life conditions. At the same time, many artists expressed cautious optimism about the future of Lebanon: for instance, Baha Boukhari used the symbol of a cedar tree in the form of a kerosene lamp (6) shining in darkness; dabbed: "ويقى لبنان" ("There is still Lebanon").

Above all, though, during and after the war, cartoonists were constantly ridiculing Arab politicians who, unlike IDF or Hezbollah, preferred compromises to military action. Hence the cartoon by Jalal ar-Rifa'y, where we can observe the collective representation of the Arab world ("solidarity" which neither of nations reaps great benefits from), who is bleeding with three streams: Lebanon, Iraq and Palestine (7).

Mocking the actual absence of the proclaimed "Arab solidarity" is a recurring motif in caricatures of the period. Thus, on the cartoon by Stavro Jabra (image 8) we see a crocodile tagged ("وزراء الخارجية العرب" - "Arabs' ministries of foreign affairs" - who sheds tears holding a sign: "نستنتكر العدوان" ("We denounce violence"); while Lebanon is smoldering on the background after a bombing.

The reader will also see similarly ironic visuals in the cartoon by Abdallah Darqawi, namely the broken umbrella tagged "الجامعة العربية" (the League of Arab Nations), which proves to be a feeble attempt to cover Gaza from the shelling.

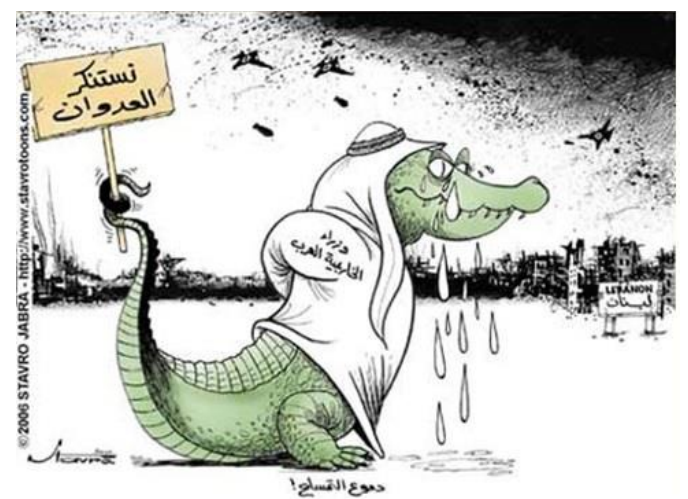

Image 8. "We condemn violence!"

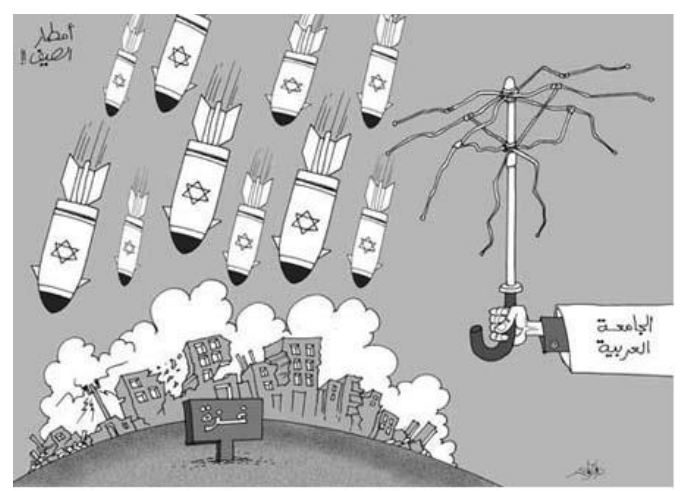

Image 9. The League of Arab Nations. Gaza

There is also a segment of the studied material dedicated to UN's policies at the time of Lebanon war. Artists, such as Hamed Najeeb (image 10) and Hamed 'Atta (image 11), have made the UN out to appear as a two-faced organization which does not function according to its own alleged values. On the cartoon by Najeeb, the reader sees the international community depicted as literally the globe who cannot pass the resolution 1701 ("الحماية الدولية لفلسطين و لبنان"), which, in fact, was intended to end the conflict; but eventually has failed, due to the veto imposed by Uncle Sam who holds the key from the Security Council in the form of the star of David [9].

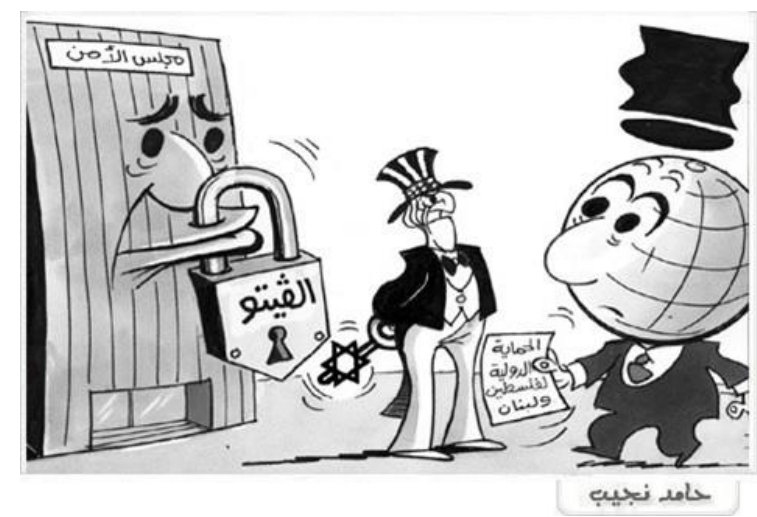

Image 10. "Veto lock vs. UN Lebanon-Palestine Resoultion" 


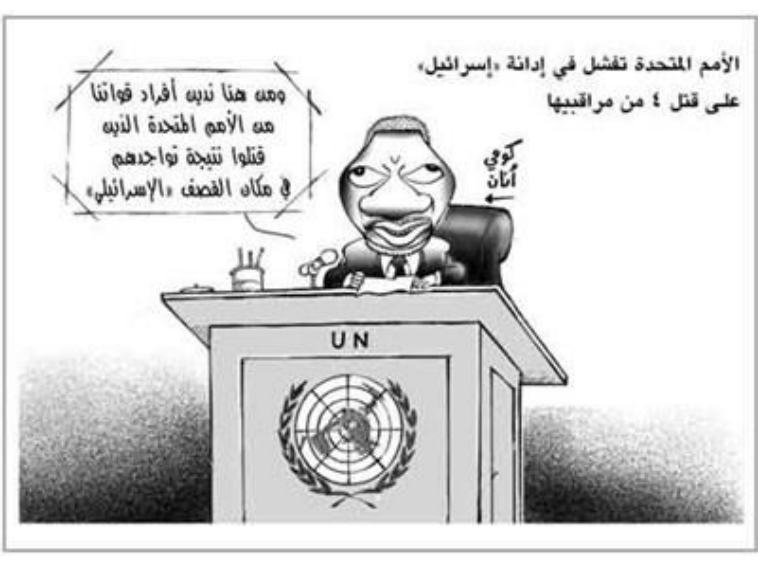

Image 11. UN: "We blame the UN troops for being killed"

Whereas on 'Atta's caricature of Kofi Annan, the acting

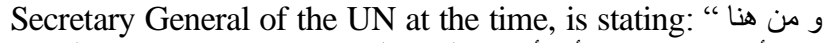
ندين أفراد قو اتتا من الأمم أمتحدة الذين قتلوا نتيجة تواجدهم في مكان القصف " - "Thus we blame the killed troops for placing themselves on the way of the shelling". The narrative of the cartoon is based on the event in summer 2006, when an Israeli bombardment hit a UN outpost by mistake and killed three workers of the UN envoy. Both in reality and cartoon, the organization failed to blame IDF for the deaths.

The aforementioned "press-meme" is afterwards mocked by Baha Boukhari (image 12), with the cartoon expressing the absurdity of the situation with a form of wordplay. Thus, the inscription on the bomb says "القنابل الغبية"stupid bombs") instead of the actual term for the type of bomb that is shown - "القنابل الذكية" (smart bombs). All the while, the blue helmets try to hide behind an excuse: “ حن دوليين و لسنابل "مدنيين ("We are internationals, not nationals"), thus refraining from taking responsibilities they were supposed to be taking.

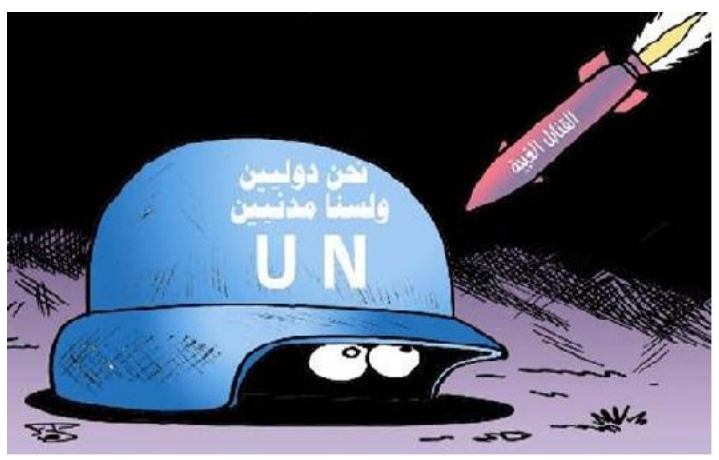

Image 12. «We are internationals, not nationals" helmet

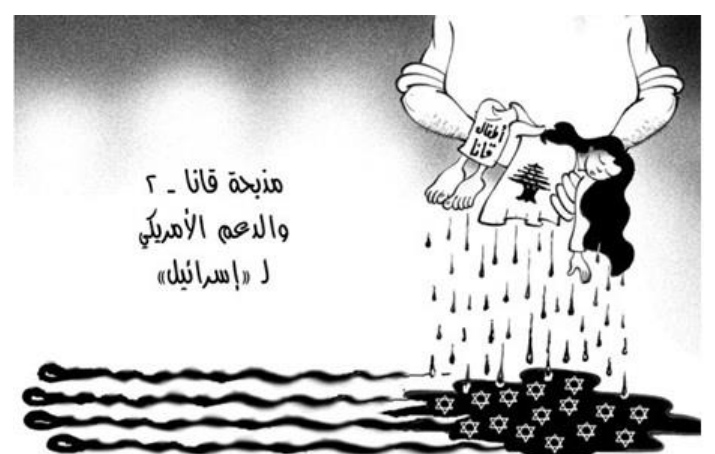

Image 13. The Qana Carnage: American support of Israel

In any case, during a war, casualties are never limited to the armies involved, or to the peacemakers' corps. As was supported by official statistics and illustrated by the artists, the substantial number of casualties among women and children was quite substantial. In this regard, the most remarkable of the mentioned works are those by Hamed 'Atta and the unknown artist $(13,14)$, displaying the impact of the tragedy of Qana which happened on the 30th of July, when an Israeli air strike killed 16 children who were buried under an apartment block [10].
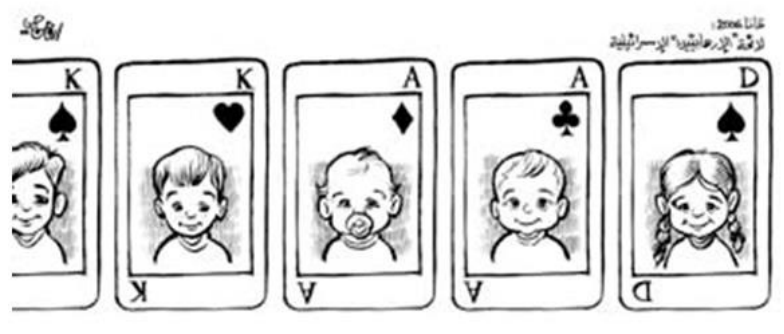

Image 14.

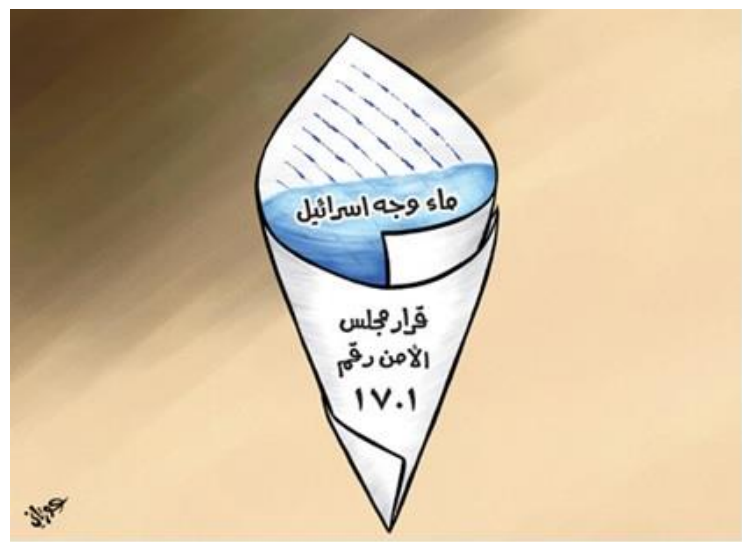

Image 15. Resolution 1701 - a vessel for the "water of the face"

Graphic content of the first picture does not need any further explanation once the observer notices the "material" that makes up the American flag. The second, however, needs to be remarked on as a prominent example of the difference between the Western and the Arabic school of caricature. While Western cartoon-makers seek to impress the public with their wit and satire, their Arabic counterparts want to shock the reader with an explicit and down-to-earth example of how tragic wartime deaths can be, without losing the sense of bitter irony. Thus, in caricature 14, the faces of children are placed on playing cards, which are a direct reference to the playing decks published in the US after the war in Iraq, featuring Saddam Hussein and his generals; dissimilar to the war in Lebanon, where the faces are somewhat more innocent.

Nevertheless, this segment of Arab political cartoons is not limited to emotional imagery - it also contains linguistic deconstruction of such known colloquial expressions of the Literary Arabic as "ماء الوجه" ("the water of the face"), i.e. the concept of saving one's good face. Caricatures by Jihad Awartani and Amjad Rasmi (image 15 and 16 respectively) show us the artists' vision of how literally such a phrase may sound through the prism of governmental propaganda.

By means of comedic inconsistency, the first cartoon portrays the infamous resolution 1701 in the form of a paper cone, which contains "the good face" of Israel. While Rasmi's visual parody represents the partnership between Israel and Uncle Sam, who seems to be losing his "water of the face" thanks to his partner. 
However, literary Arabic expressions are not the only ones that are used by artists in their continuous ridicule of different sides of the conflict. Some of the phrases are taken from Israeli propaganda, e.g. "جيش الذي لا يُقهر" (the Unbeatable army), referring to IDF's slogan [1]. However, the syntax of the sentence is quite fragile and hinges on one negative particle, as Hamed Najeeb has demonstrated in the corresponding caricature with the help of détournement par excellence - omitting a word from the widely-known slogan (17) in order to distort the message.
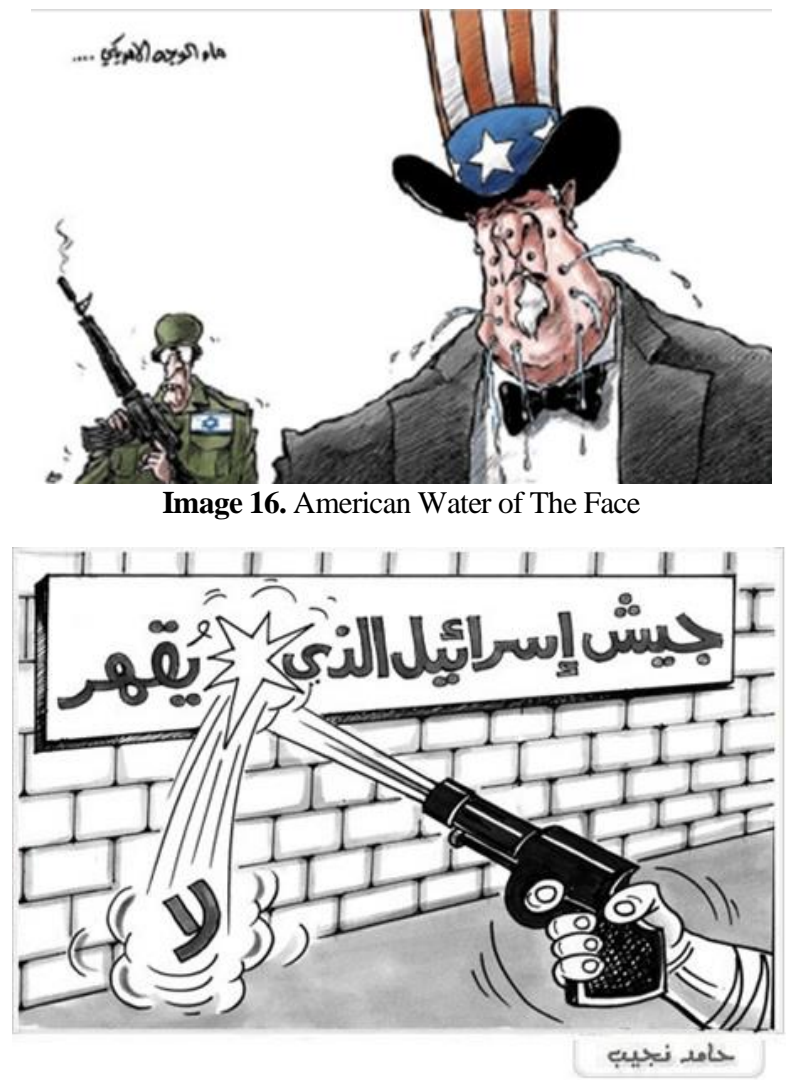

Image 17. "The army that does not win"

The same phrase is the headline for another caricature by Mohammed Seebaneh (18) - a picture of a maimed Israeli soldier, posed as a threat by the media, while not presenting any real danger to any one, on account of lacking several limbs and standing on a crutch [12].

However, the ridicule does not attack Israel exclusively. Using yet another mass-media meme - "أمطار الصيف" ("the summer rains") - the name of the Israeli operation in the Gaza sector - is interpreted by some artists not as a malevolent Israeli agenda, but as a reflection of Arab policies. Thus, a cartoon created by A'la al-Luqta (image 19) offers a visual deconstruction of the archetypal politician, i.e. an Arab political leader who is pouring the rain from his mouth onto a poor inhabitant of Palestine.

Nevertheless, the largest number of Arabic caricatures at the time displayed the artists' disaccord with the actions of the US and Israel. For instance, the following two cartoons created by Amjad Rasmi (20) and Hamed Najeeb (21). The first one depicts an Israeli general who changes his shoes for ones that seem to be of the same model, only the pair from the box is marked "الشرق الأوسط الجديد" (the new Middle East").

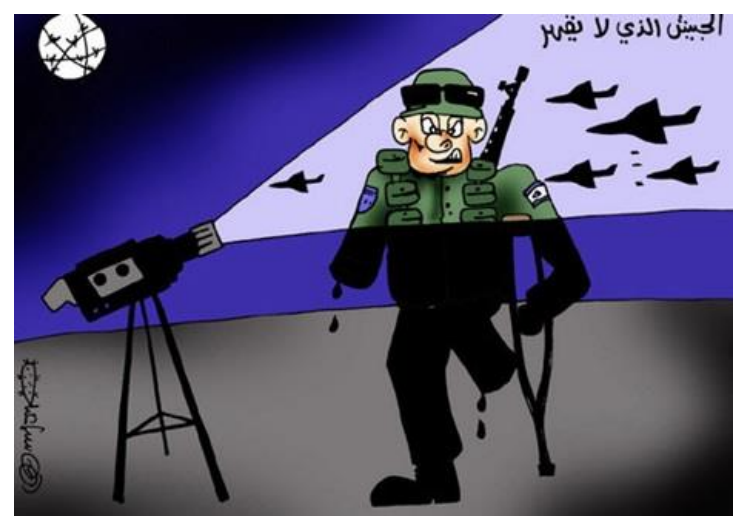

Image 18.

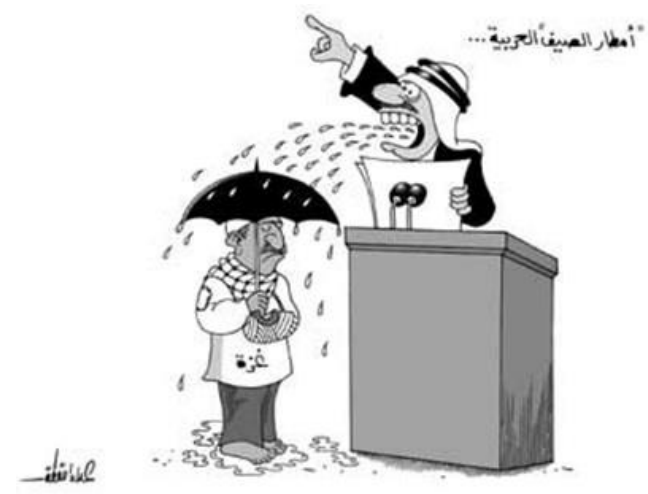

Image 19. "The Arab Rains of Summer"

"The New Middle East" was a project suggested by Condoleezza Rice, US Secretary of State in 2006, which constituted a new geo-political make-up of the Middle East and introduced an Anglo-American military roadmap for the Middle East and Central Asia. However, the project seemed to have been stalled at the time, although it did open up a new topic for ridiculing American foreign policy, which through the prism of literary deconstruction - appears to be no newer than a pair of the same shoes.

In this context, Hamed Najeeb expresses comedic inconsistency as follows: Uncle Sam is asks an Israeli soldier " مين

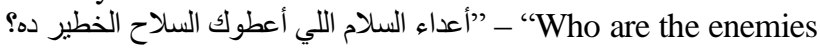
of peace who gave you these weapons?" While the bomb held by the Israeli obviously says: "Made in US".

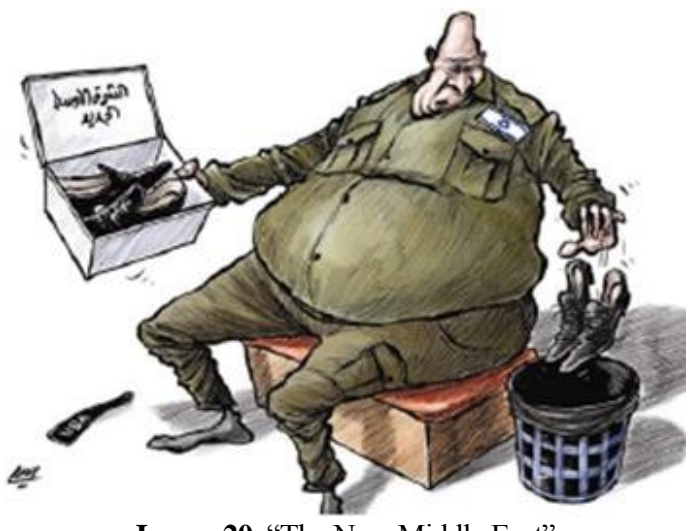

Image 20. "The New Middle East"

Thus, caricature as a combination of visual art and literature can offer great amount of scientifically intriguing material while transmitting a popular cultural opinion on any relevant matter. However, unlike visual novel and comics, political cartoon cannot depict moral ambiguity, as the latter only confirms what the readers already believe in, using 
satirically "weaponized" stylistics and slogan-like text.

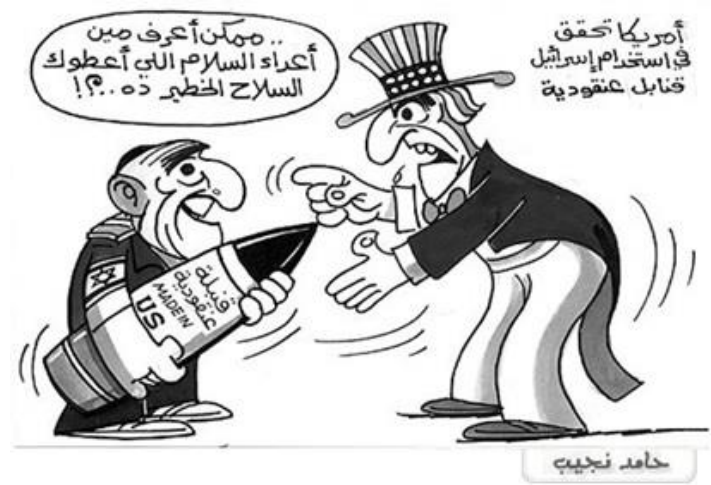

Image 21. The American-led cluster-bomb investigation:"Could you tell me who the enemy of peace, who supplied you with this bomb is?"

Therefore, the presentation is one-sided: the majority of
Arab cartoonists during Lebanon war chose to ridicule Israel and allies, and almost completely ignored the destructive role of Hezbollah in the conflict.

With regards to the artistic instruments by which Arabic political cartoons do influence the reader: they encompass literary (self-)deconstruction; icon-text, icon-icon and texttext comic inconsistency; comedic personalization, hyperbolization under the umbrella concept of Debordian détournement (distorting and "hijacking" populist slogans in one way or another). The studied imagery appears to be more blatant and literally more bloody than mainstream western analogues (depicting more blood and comic gore, dead children), turning the attention of the reader towards the emotional aspect of the social problem, instead of pointing out strictly logical discrepancies, as the latter is chiefly characteristic of western cartoonists.

\section{REFERENCES}

1. Cleveland, William. A History of the Modern Middle East. - http://aub.edu.lb.libguides.com/c.php?g=276541\&p=1842962 Westview Press, 2004

2. Douglas, Allen and Malti-Douglas, Fedwa. Arab Comic Strips: Politics of an Emerging Mass Culture, Bloomington \& Indianapolis, 1994

3. Göçek, Fatma Müge (ed.) Political Cartoons in the Middle East. Princeton, 1998

4. Hafez, Kai (ed.) Mass Media, Politics and Society in the Middle East. - Hampton Press, 2001

5. Qassim, Andreas. Arab Political Cartoons. The 2006 Lebanon War. - Lunds University Press, 2007

6. Slyomovics, Susan and Joseph (eds.) Women and Power in the Middle East. - University of Pennsylvania Press, 2001

7. ساجد الدوير. في بنت جبيل ساحة النزال الأخيرة. نسرين إدريس (Nisreen Idrees. Sajid ad-Duwayr: Bint Jbeil - The Last Battlefield). - Available at:

https://web.archive.org/web/20110303014607/http://www.bintjb eil.org/index.php?show $=$ news\&action $=$ article $\& i d=8443$

8. American university of Beirut. - Online Catalogue of Comic Books. - Available at:

9. Behind the Headlines: UN Security Council Resolution 1701. Israel Ministry of Foreign Affairs. -Available at: https://mfa.gov.il/mfa/foreignpolicy/issues/

10. Civilian Deaths in Lebanon Provoke International Outcry, Israel Suspends Aerial Bombardment. - Global Insight: 2009. Available

https://web.archive.org/web/20090108012242/http://www.global insight.com/SDA/SDADetail6485.htm

11. Débord, Guy-Ernest; Wolman, Gil J. Mode d'emploi du détournement. - Biblioteque Virtuelle. - Available at: http://sami.is.free.fr/Oeuvres/debord_wolman_mode_emploi_det ournement.html

12. Pentagon Learning from IDF's Disaster. - Y-net News. Available at: https://www.ynetnews.com/articles/0,7340,L3697924,00.html

13. Timeline of the July War 2006. - Daily Star. Available at: https://web.archive.org/web/20060928081123/http://www.dailyst ar.com.lb/July_War06.asp 